\title{
Sickle Injury to Brain
}

\author{
Mubashshir Ali*, Apoorva Kumar, Osman Musa Hingora, Faraz Ahmad \\ Department of Surgery, Era's Lucknow Medical College, Lucknow, India \\ Email: skashish2095@gmail.com
}

Received 5 October 2014; revised 5 November 2014; accepted 5 December 2014

Copyright (C) 2015 by authors and Scientific Research Publishing Inc.

This work is licensed under the Creative Commons Attribution International License (CC BY).

http://creativecommons.org/licenses/by/4.0/

(c) (i) Open Access

\begin{abstract}
We reported a case of a 12-year-old girl child with an uncommon intracranial metallic foreign body who was hit by her younger sister with sickle that got stuck to skull. Patient presented to us with stuck sickle in her head and was fully conscious with complaint of headache. She was very much afraid of her injury and was screaming with pain and fear. There was no neurological weakness. Computed tomography scan revealed that metallic foreign body was located adjacent to the confluence of major sinuses posteriorly on her skull. The location and position of foreign body suggested that it was of low velocity, and was hit from pointed end of sickle. It was taken out after doing craniectomy all around the sickle point and dural tear was repaired with pericranium. The postoperative course was uneventful.
\end{abstract}

\section{Keywords}

Brain, Foreign Body, Sickle, Head Injury

\section{Introduction}

Intracranial foreign bodies are generally due to penetrating injuries through the orbit, ear or cranial bones. Penetrating trauma secondary to gunshot wounds is a common cause of injury. However, penetrating cranio-cerebral injuries due to objects such as sickle, arrow, needle, iron rod, and piece of wood or nail are known but rare [1].

The bony cranium protects the brain from injury caused by low-velocity "domestic" foreign bodies. Their kinetic energy is low. Therefore, such foreign bodies usually gain access to the cranial cavity through areas of naturally occurring communication such as the open cranial sutures of infants. Sometimes these foreign bodies are intentionally introduced in small infants through fontanel as mean of attempted infanticide. These types of foreign bodies are usually detected accidentally, most often after minor head injury necessitating plain cranial radiography.

The management of retained foreign body is controversial. Most of the information available on this subject

"Corresponding author.

How to cite this paper: Ali, M., Kumar, A., Hingora, O.M. and Ahmad, F. (2015) Sickle Injury to Brain. Open Journal of Modern Neurosurgery, 5, 23-26. http://dx.doi.org/10.4236/ojmn.2015.51004 
comes from reports of penetrating injuries from war wounds or civilian high-velocity projectiles [2]. In studies of war injuries, Cushing cautioned against the potential danger of aggressively removing a foreign body in patients with penetrating injuries [3]. Cushing's conservative approach has been supported by studies from more recent armed conflicts on penetrating high-velocity missiles injuries [4]. On the basis of these studies, thorough debridement of the superficial wound tract without aggressive removal of a deeply located retained foreign body has been advocated.

\section{Case Report}

A 12-year-old girl, who was a student in a traditional small village of eastern part of India presented to us with stuck sickle in her head. She was fully conscious with complaint of local pain. She was very much afraid of her injury and was screaming with pain and fear. She belonged to a farmer family and there were many agricultural instruments at her home. Her younger sister hit her out of anger with that sickle.

On admission, her general physical status was found to be normal. She was conscious, alert and cooperative. She did not have any physical sign suggestive of serious intracranial injury. The patient had no evidence of intellectual problem, delayed growth or mental retardation. Neurological examination did not show any abnormality. A sickle with its wooden blade was attached to posterior part of head while the tip was inside the cranium (Figure 1 and Figure 2).

Three-dimensional cranial computed tomography (CT) was performed to further evaluate the presence of the foreign objects in the cranium. A CT scan showed metallic foreign body located adjacent to the confluence of major sinuses posteriorly on her skull (Figure 3 and Figure 4).

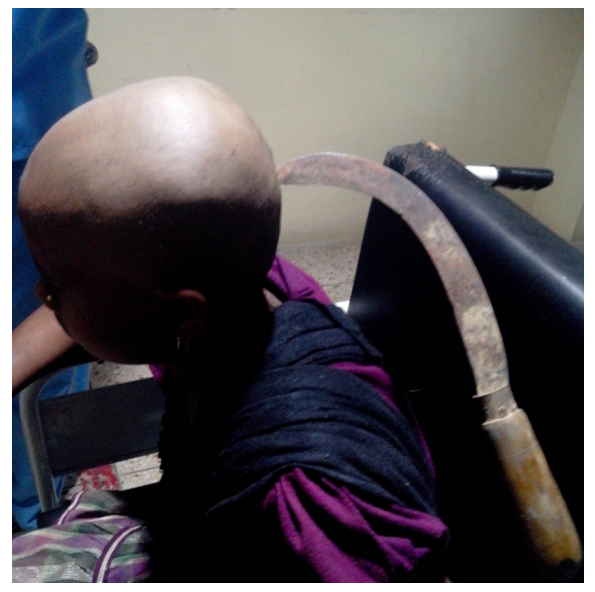

Figure 1. Side view of sickle stuck to the back of head while patient is sitting on chair.

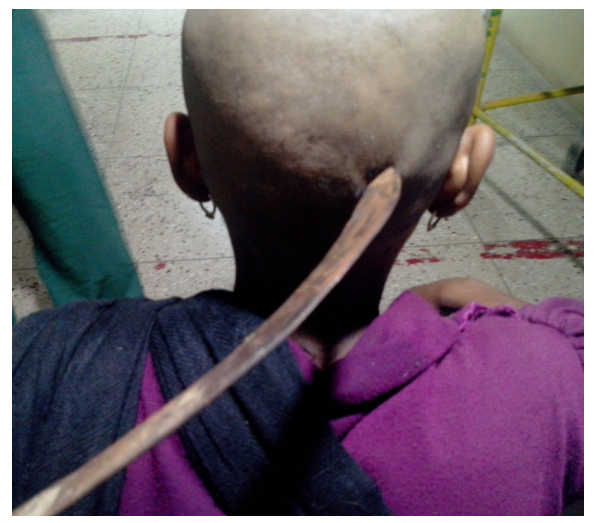

Figure 2. Sickle seen from back attached to the head while the tip is inside. 


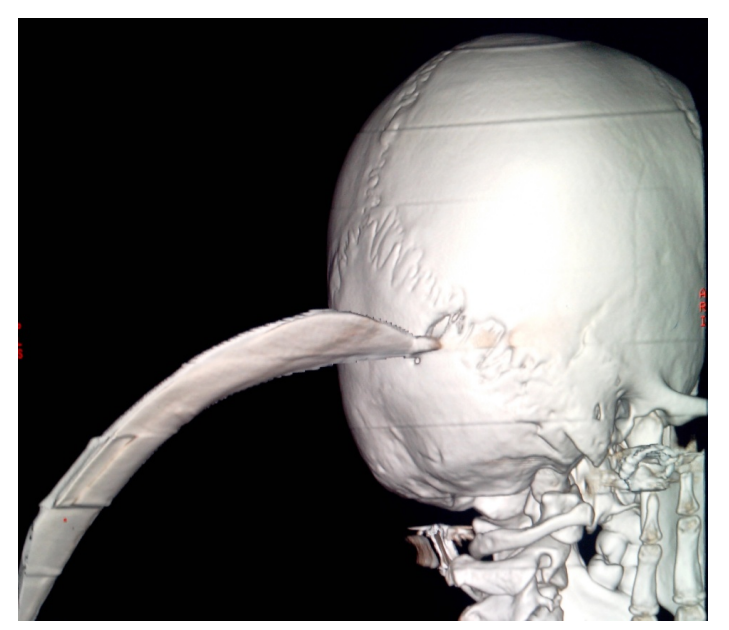

Figure 3. 3D reconstruction of skull showing sickle entering just below the right lambroid suture.

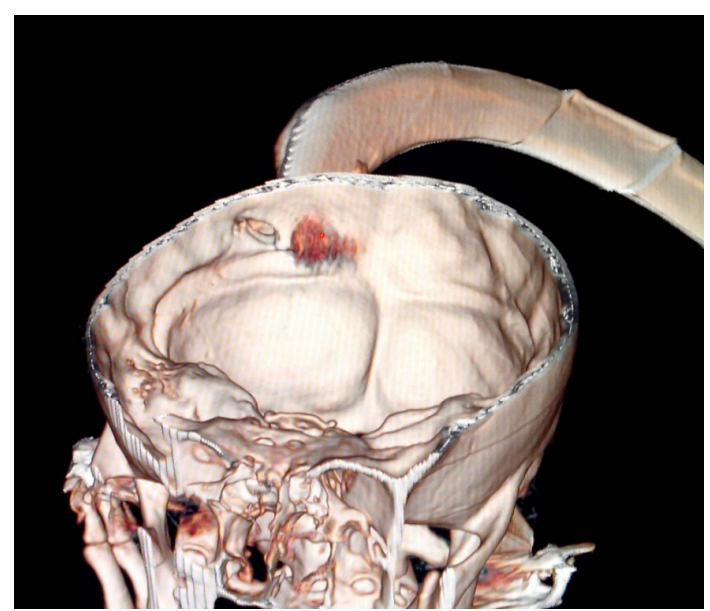

Figure 4. 3D reconstruction of cranium showing the tip of sickle just above the right transverse sinus.

After initial workup she was posted for removal of foreign body. Patient was shifted to operation room after head shaving. A small craniectomy was done adjacent to injury site and sickle was removed. There was small rent in dura mater, which was repaired by small pericranial graft. Foreign body was handed over to police for medico legal purpose. Postoperative course was uneventful.

\section{Discussion}

Penetrating non-missile intracranial injuries caused by metallic foreign body are very rare among civilians. A variety of penetrating objects of the skull and brain have been reported, including blade, nail, pencil, splinter of wood and wire. Intracranial foreign bodies are usually due to penetrating injuries through the cranial bone, orbit and ear. It has also been reported that surgical objects may be left in the brain during surgery [5]. The route of penetration of a foreign body can be judged by its position. For example sewing needle is usually inserted into the brain through open anterior fontanel as a form of child abuse [6]. A careful preoperative assessment of the physical features of the foreign body, the trajectory of the injury and the anatomical structures likely to be involved is essential to avoid injury to the surrounding normal brain tissue. A careful radiological investigation must be completed before the extraction of the impacted metallic foreign body to identify the safest route for its removal. Special attention must be paid to avoid undue movements of the sharp edges of the object that could cause secondary damage to the pericontusional brain tissue [7]. The aim of the surgical approach is to minimize 
the damage to the pericontusional brain tissue, by pulling the metallic handle out from the brain through the same trajectory it had followed after impact.

In clinical practice, many physicians prefer magnetic resonance imaging (MRI) to evaluate intractable headache. It might be possible to see cases like that of our patient especially in developing countries and MRI could have disastrous consequences. Therefore, it becomes more important to make a gradual evaluation of pain step by step and an MRI should not be ordered immediately.

\section{Conclusion}

Although the prevalence of cases of intracranial foreign body is not common in the literature, this may be due to the low associated survival rate. Surviving cases are mostly diagnosed by skull radiography after minor head injury. In our case general physical status was found to be normal. She was conscious, alert and cooperative. She did not have any physical sign suggestive of serious intracranial injury and during operation there was small dural rent with underlying minimal cerebral contusion.

\section{References}

[1] Pelin, Z. and Kaner, T. (2012) Intracranial Metallic Foreign Bodies in a Man with a Headache. Neurology International, $5,18$.

[2] Lanzino, G., Lemole Jr., G.M., Henn, J.S. and Zabramski, J.M. (2002) An Unusual Foreign Body in the Brain. Barrow Quarterly, 18.

[3] Cushing, H. (1918) Notes on Penetrating Wounds of the Brain. British Medical Journal, 298, 221-226. http://dx.doi.org/10.1136/bmj.1.2982.221

[4] Brandvold, B., Levi, L., Feinsod, M., et al. (1990) Penetrating Craniocerebral Injuries in the Israeli Involvement in the Lebanese Conflict, 1982-1985. Analysis of a Less Aggressive Surgical Approach. Journal of Neurosurgery, 72, 15-21. http://dx.doi.org/10.3171/jns.1990.72.1.0015

[5] Askenasy, H.M., Kosary, I.Z. and Braham, J. (1961) Sewing Needles in the Brain with Delayed Neurological Manifestation. Journal of Neurosurgery, 18, 554-556. http://dx.doi.org/10.3171/jns.1961.18.4.0554

[6] Sener, R.N. (1997) Intracranial Sewing Needles in a 20-Year-Old Patient. Journal of Neurosurgery, 24, 212-214.

[7] Rao, G.P., Rao, N.S. and Reddy, P.K. (1998) Technique of Removal of an Impacted Sharp Object in a Penetrating Head Injury Using the Lever Principle. British Journal of Neurosurgery, 12, 569-571. http://dx.doi.org/10.1080/02688699844457 
Scientific Research Publishing (SCIRP) is one of the largest Open Access journal publishers. It is currently publishing more than 200 open access, online, peer-reviewed journals covering a wide range of academic disciplines. SCIRP serves the worldwide academic communities and contributes to the progress and application of science with its publication.

Other selected journals from SCIRP are listed as below. Submit your manuscript to us via either submit@scirp.org or Online Submission Portal.
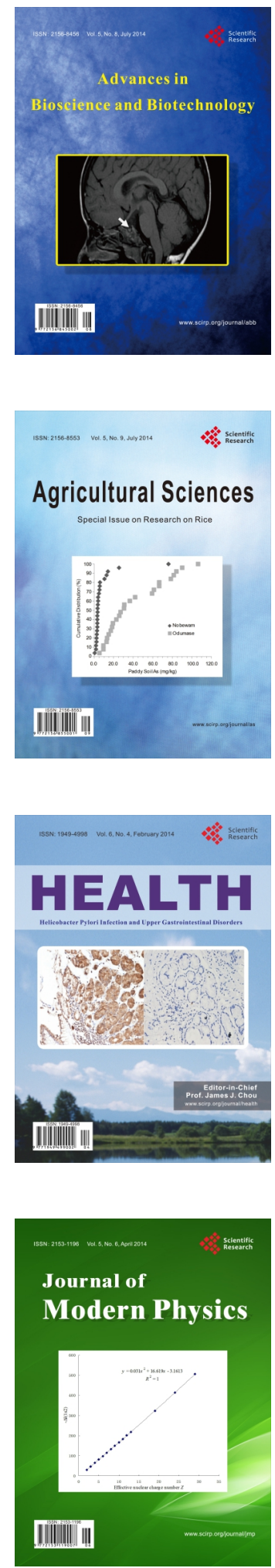
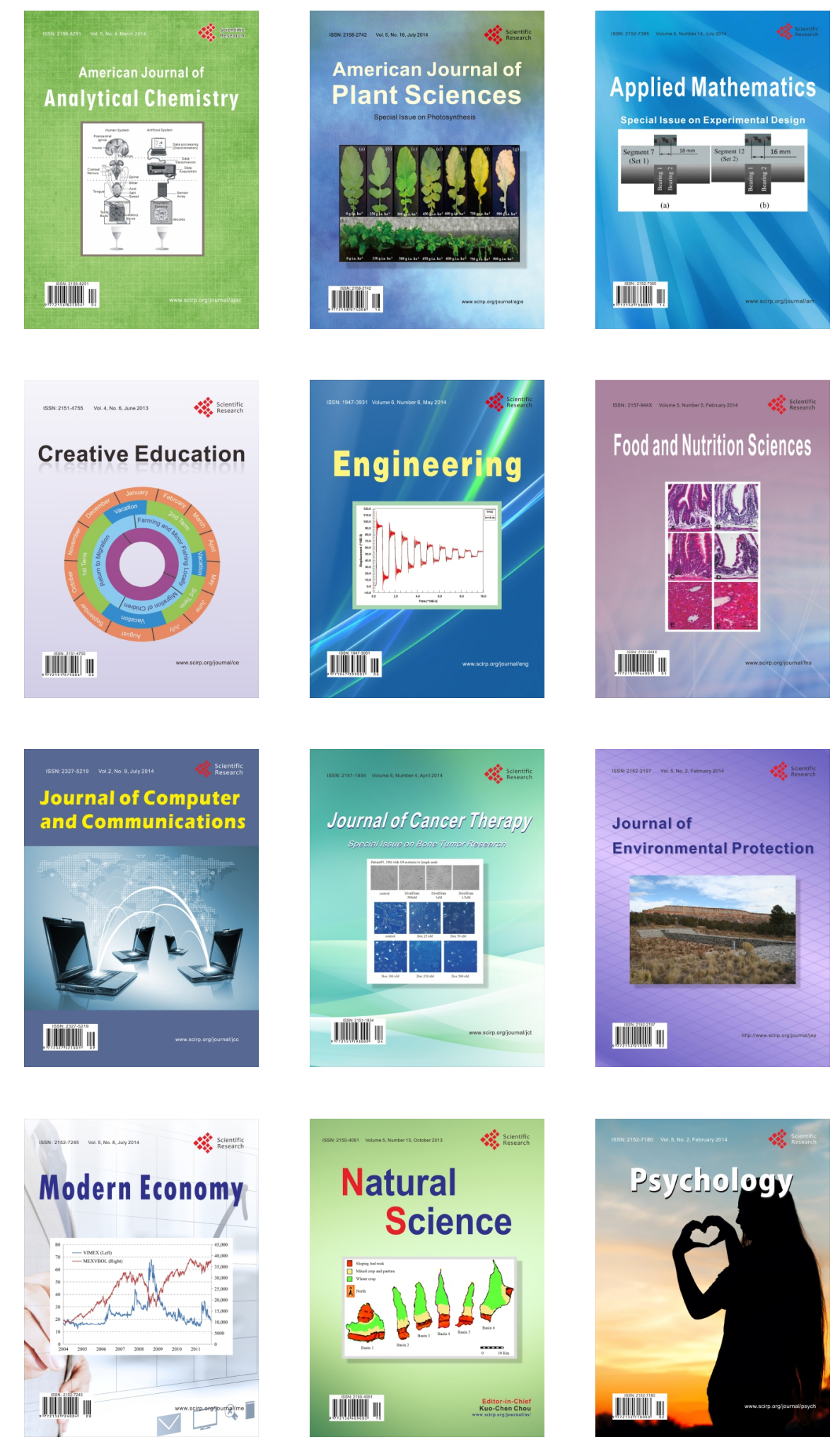